\title{
Hollow Cathode Assembly Development for the HERMeS Hall Thruster
}

\author{
Timothy R. Sarver-Verhey ${ }^{1}$ and Hani Kamhawi ${ }^{2}$ \\ NASA Glenn Research Center, Cleveland, OH, 44135 \\ Dan M. Goebel ${ }^{3}$ and James E. Polk ${ }^{4}$ \\ Jet Propulsion Laboratory, California Institute of Technology, Pasadena, CA, \\ and \\ Peter Y. Peterson ${ }^{5}$ and Dale A. Robinson ${ }^{6}$ \\ Vantage Partners, LLC \\ NASA Glenn Research Center, Cleveland, OH, 44135
}

\begin{abstract}
To support the operation of the HERMeS $12.5 \mathrm{~kW}$ Hall Thruster for NASA's Asteroid Redirect Robotic Mission, hollow cathodes using emitters based on barium oxide impregnate and lanthanum hexaboride are being evaluated through wear-testing, performance characterization, plasma modeling, and assessment of system implementation concerns. This paper will present the development approach used to assess the cathode emitter options. A 2,000-hour wear-test of development model barium-oxide-based (BaO) hollow cathode is being performed as part of the development plan. The cathode was operated with an anode that simulates the HERMeS hall thruster operating environment. Cathode discharge performance has been stable with the device accumulating $\mathbf{7 4 0}$ hours at the time of this report. Cathode operation (i.e. discharge voltage and orifice temperature) was repeatable during period variation of discharge current and flow rate. The details of the cathode assembly operation during the wear-test will be presented.
\end{abstract}

${ }^{1}$ Ion Propulsion System (IPS) Cathode Lead, Electric Propulsion Systems Branch, AIAA Senior Member.

${ }^{2}$ IPS Thruster Deputy Lead, Electric Propulsion Systems Branch, AIAA Associate Fellow.

${ }^{3}$ IPS Thruster Diagnostics and Cathode Engineer and Senior Research Scientist, AIAA Fellow.

${ }^{4}$ IPS Deputy Lead, Propulsion, Thermal, and Materials Engineering Section, AIAA Fellow

${ }^{5}$ Research Engineer, Electric Propulsion Systems Branch, AIAA Senior Member.

${ }^{6}$ Technical Draftsman 


\section{Nomenclature}

ARM $=$ Asteroid Redirect Mission
ARRM $=$ Asteroid Redirect Robotic Mission
BaO $=$ Barium-oxide-based impregnate
DAQ $=$ Data Acquisition Unit
DCA $=$ Discharge Cathode Assembly
GRC $=$ Glenn Research Center
HERMeS $=$ Hall Effect Rocket with Magnetic Shielding
ISS $=$ International Space Station
JPL $=$ Jet Propulsion Laboratory
LaB6 $=$ Lanthanum Hexaboride
NEXT $=$ NASA's Evolutionary Xenon Thruster
NSTAR $=$ NASA Solar Technology Application Readiness
TDU $=$ Technology Development Unit

\section{Introduction \& Background}

To meet the propulsion requirements of the NASA Space Technology Mission Directorate (STMD) sponsored Solar Electric Propulsion Technology Demonstration Mission (SEP TDM) project, a joint team of NASA Glenn Research Center (GRC) and Jet Propulsion Laboratory (JPL) technologists is developing the Hall Effect Rocket with Magnetic Shielding (HERMeS) thruster. The key driving requirements for the Asteroid Redirect Robotic Mission (ARRM) Ion Propulsion System are that it must be single fault tolerant while processing up to 5,000 kg of xenon over an input power range of 6.67 to $40 \mathrm{~kW}$. The required propellant throughput capability of the IPS is 5,000 $\mathrm{kg}$, by far the largest propellant throughput processed by an electric propulsion system. ${ }^{1}$ The individual HERMeS thrusters must operates at $12.5 \mathrm{~kW}$ with a specific impulse of up to 2600 seconds and can process up to $1780 \mathrm{~kg}$ of xenon. A critical component of the HERMeS thruster is a centrally-mounted hollow cathode which generates the charged particles necessary for efficient operation of this thruster. The SEP TDM project had initially required that the hollow cathode be capable of operating for at least 50,000 hours in order for the HERMeS thruster to process the required amount of xenon. ${ }^{1}$ While recent decisions have reduced both this life target as well as the required emission current from the hollow cathode (due to changes in the accelerating voltage), reliable, long duration operation remains its primary requirement.

Two cathode emitter technologies are under investigation for use in hollow cathode assembly for the HERMeS thruster. Based on successful implementation in ground testing, a hollow cathode configuration derived from the NEXT Discharge Cathode Assembly (DCA) was developed. The NEXT gridded ion thruster successfully completed 
a Long Duration Test during which 51,184 hours of operation were accumulated on the DCA. ${ }^{2}$ Over the course of the test, the DCA was operated at similar conditions as the cathode used in the HERMeS thruster. Emission current magnitude drives the cathode operating temperature, which, in turn, determines emitter life. Hence the use of barium oxide-based emitter technology is considered a low technical risk for this application. The second option is LaB6 that has been used as the emitter in the Stationary Plasma Thruster electric thrusters; advanced thruster development; and extensively in ground uses in vacuum electronics. LaB6 emitters are attractive because of the capability for much higher emission currents at a comparable size as well as significantly reduced sensitivity to contamination by oxygen. ${ }^{3}$ Operationally identical hollow cathode assemblies have been fabricated and are being tested. The LaB6 cathode wear-tests are reported in a companion paper by one of our co-authors. ${ }^{4}$

To assess the capability of each of these emitter options to meet the requirements for the HERMeS thruster project, the technology readiness was determined through three activities. First, component wear-testing is underway. Because the HERMeS thruster power is greater than has been previously validated for long life operation, 2,000 hour wear-tests of the $\mathrm{LaB} 6$ and $\mathrm{BaO}$ cathodes are being performed to identify any new wear mechanisms that may impact cathode life. Additionally, cyclic testing of the LaB6 heater required for cathode ignition is underway to demonstrate adequate life. ${ }^{5}$ This cyclic testing is being performed in test facilities that enable the heater to be thermally cooled to space-like conditions $\left(-10\right.$ to $-100{ }^{\circ} \mathrm{C}$ ) to better simulate space conditions. Multiple heaters are being tested to obtain the information needed to assess their cycle life. Another 2,000-hour wear-test of the LaB6 hollow cathode has been performed to verify emitter life when operated with oxygen-doped xenon to simulate less stringent propellant purities conditions. ${ }^{4}$

Wear-tests to date have been limited to development model cathode assemblies that were deemed of sufficient fidelity to assess wear mechanisms of the emitter and orifii. The second activity is to investigate factors specific to cathode interactions with the thruster, engineering-level designs for the hollow cathode have been generated and evaluated through significant structural and thermal analyses to ensure compatibility with the HERMeS thruster. While engineering model hardware has not been fabrication, it is expected that completing the engineering model designs will significantly advance the maturity of these components. An example of this design is illustrated in Figure 1. 


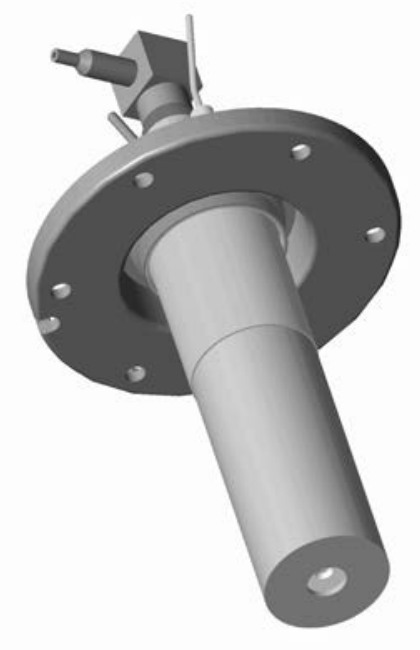

Figure 1. Advanced Hollow Cathode Assembly Design for HERMeS Thruster

The third activity seeks to provide critical information on risk assessment of the emitter options related to factors outside the planned testing activities detailed above. The implementation benefits and constraints (for example, propellant purity requirements) of each of the emitter options will be assessed through a review of technology heritage, investigation of past practices in government and commercial spacecraft, and discussions with vendors. The down-select of the emitter options is currently underway and the thruster team expected to make a selection and recommendations to the HERMeS project is expected later in the summer of 2016.

\section{Testing Description}

\section{A. Hollow Cathode Assembly}

The hollow cathode is a refractory metal tube with a refractory metal plate with a refractory metal plate at the downstream end. The plate has a restricting orifice through which a propellant gas, typically an inert gas such as xenon, is exhausted after being delivered from upstream. The cathode orifice maintains the tube interior at a higher pressure to enhance the generation of plasma inside the cathode. Immediately upstream of the orifice plate, a cylindrical emitter composed of a low-work material is positioned at the downstream end of the cathode tube. The emitter provides enhanced electron emission under direct heating that enables an efficient creation of plasma. The necessary heating is provided either by a heater located on the exterior of the cathode tube or generated due to ion bombardment when the discharge is present. ${ }^{6}$ Charged particles are expelled from this internal plasma through the cathode orifice to sustain the discharge plasma within the Hall thruster.

The emitter investigated for this report is a sintered tungsten matrix cylinder that has been impregnated with a mixture of Barium Oxide, Calcium Oxide, and Aluminum Oxide. The impregnate used in this emitter is commonly referred to by its molar concentration of 4-1-1. The 411 impregnated emitters have been employed for decades in as the cathode element in vacuum tubes. ${ }^{7}$ NASA GRC has used this type of emitter extensively in the ISS Plasma Contactor project ${ }^{8}$, for the NSTAR thruster used on the Deep Space $1{ }^{9}$ and Dawn ${ }^{10}$ missions, and in the development of the NEXT ion thruster. ${ }^{11}$ Through the course of these missions, an extensive body of operational data on hollow cathodes using impregnated emitters has been obtained, which has been used to define and qualify processing 
requirements (handling, operation, storage) that have been demonstrated to provide long-life cathode/emitter operation.

A tantalum cylinder ('emitter retainer') machined to fit within the cathode tube and reduce thermal conduction from the emitter is positioned between the upstream end of the emitter and a flange to which the cathode is mounted. When the gas flange has been connected to the its mating surface, the emitter retainer is compressed to maintain the emitter in position during the thermal cycling that occurs during testing.

A coaxial heater fitted to the exterior of the cathode tube provides the energy to drive the emitter to target temperatures required for reliable discharge ignition and safe operation. This coaxial element is comprised of refractory metal sheath and center conductor, along with a ceramic insulator.

A graphite keeper shell encloses the cathode and heater and has an orifice aligned with the cathode tube orifice. The keeper is attached to an isolating alumina split ring assembly, which is secured to the cathode tube upstream of the heater assembly. A transition cylinder brazed to the upstream end of the refractory cathode tube that allows an adapter flange to be welded to the tube assembly. The mating flange both secures the emitter and emitter retainer inside the cathode tube and provides a gas-tight connection to the propellant feed-system. The development model hollow cathode installed in the test stand is shown in Figure 2.

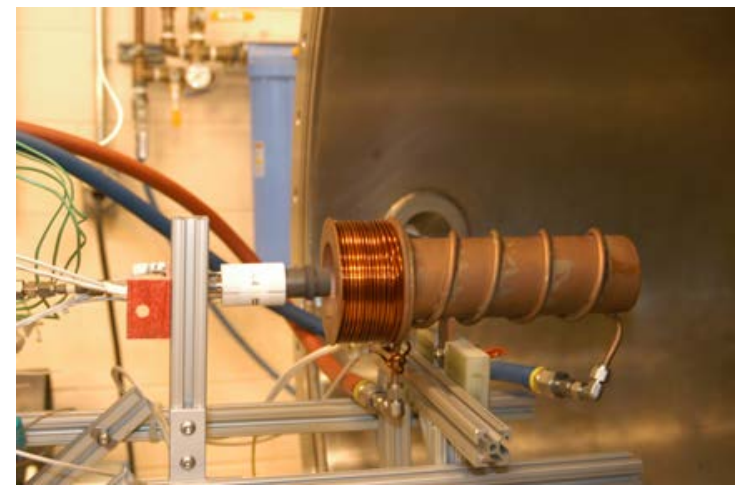

Figure 2 Development model Hollow Cathode Assembly with Thruster Simulator Anode in test configuration

\section{B. Cathode Configuration Determination}

Hollow cathodes have been successfully employed as plasma sources in electric thrusters for many years. From this experience, sizing relationships were developed to determine the elements of the hollow cathode geometry that enable reliable, long-life operation. For the present activity, two sets of development level hollow cathodes were fabricated with different cathode orifice sizes. One set of cathodes was fabricated that used the barium-impregnate-based emitter, while a second set was used LaB6 emitters. The LaB6 test program is reported in a companion paper ${ }^{5}$ while this report will focus on the $\mathrm{BaO}$ cathode results. The cathode orifice sizes investigated are listed in Table 1 where the values have been normalized to the orifice size selected. 
Table 1 Hollow Cathode Orifice Sizes

\begin{tabular}{|c|c|c|}
\hline Configuration & BaO & LaB6 \\
\hline 1 & $100 \%$ & $100 \%$ \\
\hline 2 & $83 \%$ & $158 \%$ \\
\hline 3 & $58 \%$ & \\
\hline
\end{tabular}

The cathode orifice investigation was performed through a series of emitter temperatures measurements and internal plasma measurements made during cathode operation over the target emission current range. The experimental approach to making these emitter temperature measurements is discussed in report prepared by thruster team members at the JPL facility. ${ }^{12,13}$ The reader is directed to these reports for complete explanation of the experimental measurements. Further discussion of the results of these measurements will be presented in the Results section.

\section{Thruster Simulator Anode}

Testing of the $\mathrm{BaO}$ hollow cathode assembly is being performed in a dedicated test stand with a Hall thruster simulator anode. This anode consisted of a copper cylinder mounted concentrically to the cathode. A magnet coil was installed at near end of the anode. The cathode assembly was installed such that the keeper face is coincident with the entrance plane of the anode/coil. This configuration is shown schematically in Figure 3, and on the right side of the photograph in Figure 2.

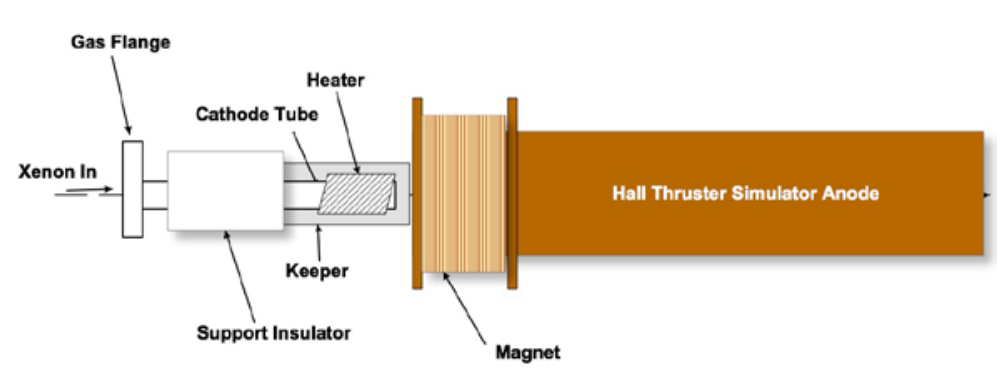

Figure 3. Schematic of the Hall Thruster Simulator Anode. The hollow cathode assembly is position on the left pointing into the anode channel

The magnet coil was powered to the conditions required to create a magnetic field at the entrance plane of the simulator anode equivalent to the HERMeS development model thruster operating at the nominal wear-test condition. Modeling of the cathodethruster anode configuration verified that the near-field regions should accurately reflect actual thruster performance. ${ }^{14}$ Consequently, erosion behavior in the cathode orifice and keeper orifice regions is being investigated during hollow cathode wear-testing to identify possible life limitations.

\section{Testing Configuration, Power, Propellant Feed, and DAQ Systems}

The cathode assembly and anode are electrically isolated from the test facility. The electrical configuration of the test article is shown schematically in Figure 4. Four power supplies were used for this wear-test: 1) a 60 VDC, 40 ADC power supply provided the discharge power; 2) a 300 VDC, 3.5 ADC power supply was used for cathode 
keeper required for cathode ignition and for providing supplemental current when the discharge current was less than 6 ADC; 3) 60 VDC, 18 ADC power supply for the cathode heater; and 4) a 60 VDC, 40 ADC power supply to provide the magnet coil current for the thruster anode simulator assembly.

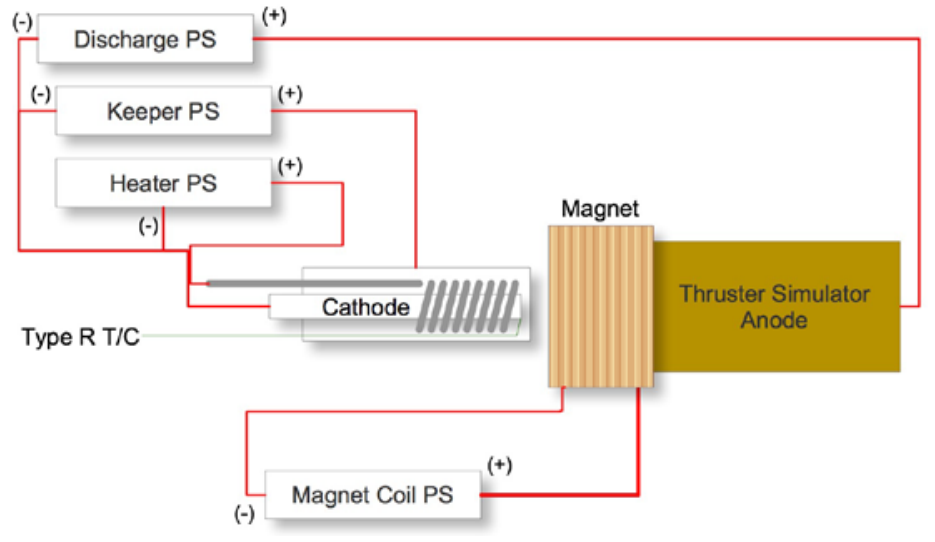

Figure 4. Hollow Cathode - Anode Electrical Schematic

Operating parameters are measured at the electrical pass-through flange on the test facility interface. These voltage signals are sent directly to a data acquisition (DAQ) unit, except for the keeper voltage, which requires a voltage divider circuit to reduce the measured voltage to allowable value. A type $\mathrm{R}$ thermocouple is spot-welded to the orifice tip/tube wall. The thermocouple extension wire also connected directly into the DAQ unit. AC behavior was monitored on a 4-channel oscilloscope with 10x voltage probes and a 100x current probe. Other parameters monitored include xenon flow rate with an electronic mass flow controller and the facility pressure with an ionization vacuum gauge.

Xenon gas was delivered to the HCA through the propellant feed system. This system, typical of cathode and thruster testing performed at GRC, is comprised of stainless steel tubing and a series of manual hand valves for controlling gas entry to different sections. An electronic mass flow controller was used to regulate the xenon flow during the wear-test. A recently purchased bottle of 99.9995\% purity xenon was integrated into the feed-system. Standardized procedures for cleaning and integrity qualification were used prior to the wear-test to document the feed-system condition. These procedures included collection of xenon gas samples which were verified by a commercial vendor to meet purity specifications.

\section{E. Test Facility}

The test facility is $1.0 \mathrm{~m} \mathrm{X} 1.0 \mathrm{~m}$ cylindrical chamber with a 10 " cryogenic pump mounted on top. The vacuum pump has a pumping speed of 4,000 L/s $\mathrm{N}_{2}$ and can evacuate the test volume to $2.5 \times 10^{-6}$ Torr with no flow and 4.5 $\mathrm{x} 10^{-4}$ Torr during the wear-test conditions. The test facility is shown in the photograph in Figure 5. 


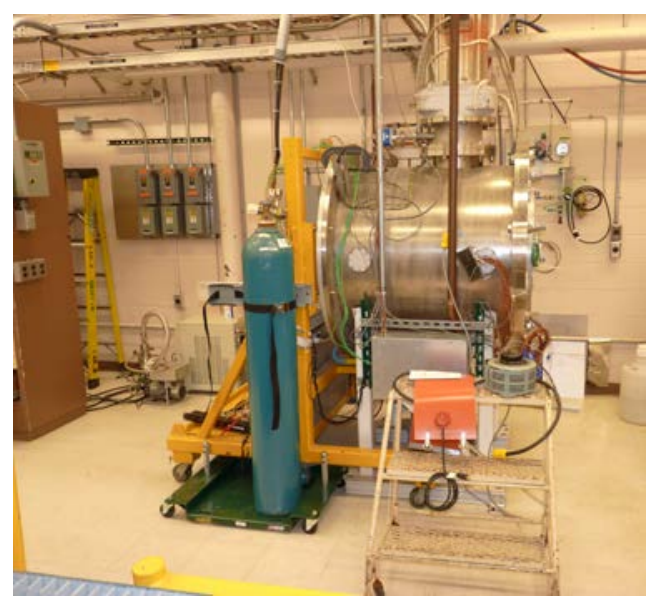

Figure 5. Wear Test Stand facility

\section{F. Hollow Cathode Operating Conditions}

The hollow cathode assembly was operated at conditions equivalent to at the nominal run condition for the HERMeS thruster Test Demonstration Unit \#1 wear-test. ${ }^{15}$ The discharge current was maintained at 24.8 ADC. This value incorporates a current contribution of approximately 2.2 ADC to account for the discharge oscillations that occur when operating in the HERMeS thruster. This added current provides an additional heat flux into the cathode emitter that is expected to provide equivalent behavior during component wear-testing where the oscillations are not present. This work was performed by will be presented one of the co-authors in a future report. The other independent parameters include the xenon flow rate (set to $7 \%$ fraction of the total flow to the thruster) and the magnet field strength controlled by the coil current setting. The field was matched to the centerline magnitude as measured in the development thruster. The DAQ system monitors several parameters during cathode operation (discharge voltage and discharge current, keeper voltage, flow rate, temperature, and facility pressure) and will shut down the power supplies in the event of off-nominal conditions.

\section{G. Wear Test Plan}

The planned time line of the wear-test is illustrated in Figure 6. After the first start, the cathode was allowed to stabilize ('burn-in’) for 50-100 hours at which time a performance characterization was performed.

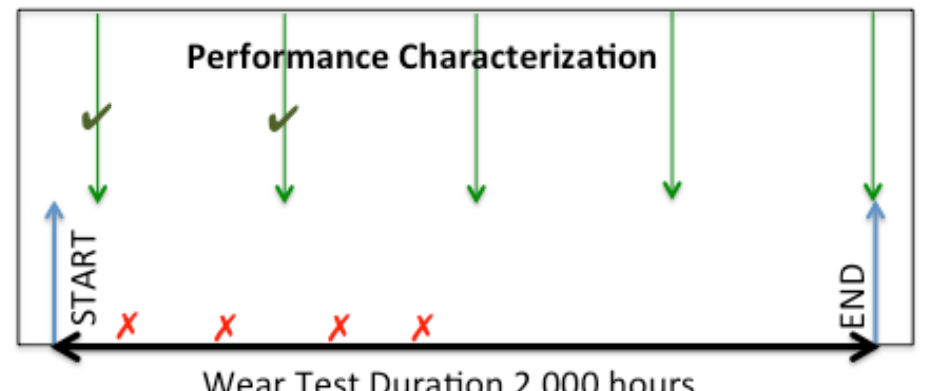

Figure 6. Wear-test Timeline. The green arrows indicate the performance characterizations performed at 500-hour intervals ( 2 completed). The red Xs indicate unplanned shut-downs.

This characterization consisted of operating the cathode at all of the conditions shown in Table 2. 
Table 2 Cathode Performance Characterization Operating Conditions

\begin{tabular}{|c|c|c|c|c|c|c|c|}
\hline 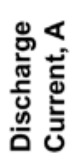 & 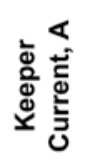 & 4.6 & 6.4 & 10.6 & 13 & 14.7 & 16 \\
\hline 6.2 & 0,2 & & & & & & \\
\hline 15 & 0 & & & & & & \\
\hline 22.1 & 0 & & & & & & \\
\hline 24.8 & 0 & & & & & & \\
\hline 27.3 & 0 & & & & & & \\
\hline 31.3 & 0 & & & & & & \\
\hline 0 & $3^{*}$ & & & & & & \\
\hline 0 & $2^{*}$ & & & & & & \\
\hline
\end{tabular}

The characterization was repeated at 500 hours intervals to document the performance stability over time. Keeper only operation of the $\mathrm{BaO}$ hollow cathode with of 2 and 3 ADC was performed to directly duplicate the cathode behavior with the HERMeS TDU-1 thruster currently being wear-tested. Additionally, the measurements were made with and without the magnetic field (indicated by asterisk in Table 2). The wear-test has achieved 743 hours at the time of this report.

\section{Results \& Discussion}

\section{A. Cathode Characterizations}

Critical measurements of emitter operating temperatures and internal plasma conditions were performed to verify that the emitters were operating at the required conditions for long-life. The primary condition was not exceeding the maximum temperature allowed for dispenser cathodes. Additionally, cathode operation needed to ensure that the internal plasma is distributed over much of the emitter surface (and not concentrated at a small surface area). The temperature distributions for two $\mathrm{BaO}$ cathodes that have been measured to date are shown in Figure 7.

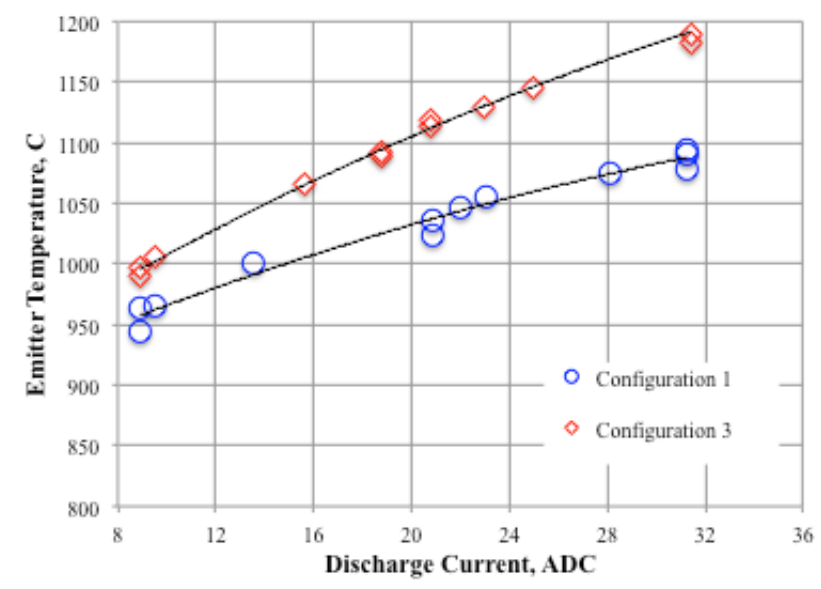

Figure 7. Emitter Surface Temperature measured with optical pyrometer

Configuration 1, with the largest cathode orifice size investigated was selected for further testing because the emitter temperatures remained below the maximum operating temperature recommended for safe operation of these materials ${ }^{16}$ over the full operating range. As can be seen in Figure 8, the configuration 1 cathode operated below the maximum temperature of $1150{ }^{\circ} \mathrm{C}$ over the entire emission current 
range, while configuration 3 cathode exceeds the temperature limit at discharge currents over approximately 25 ADC. The remaining cathode configuration, \#2, listed in Table 1 will be tested in the near future. It is expected to operate with emitter temperatures between the other two cathodes.

The results of the plasma measurements are presented in a companion paper. ${ }^{4}$ These measurements showed that plasma was distributed throughout the emitter region thereby indicating that emission is not localized to a small region where emitter temperatures could exceed the maximum allowable temperature. For the configuration 1 cathode, the plasma distribution was effectively flat. Consequently, configuration 1 was selected for the HERMeS thruster and is used in the $\mathrm{BaO}$ cathodes currently under test.

\section{B. Wear-test Behavior}

The cathode behavior is illustrated through the discharge voltage, cathode orifice plate temperature, and keeper voltage as functions of elapsed time in Figures 8-10. Other parameters captured during the wear-test include: discharge current, magnet coil current and voltage, and the AC component of discharge and keeper voltages and

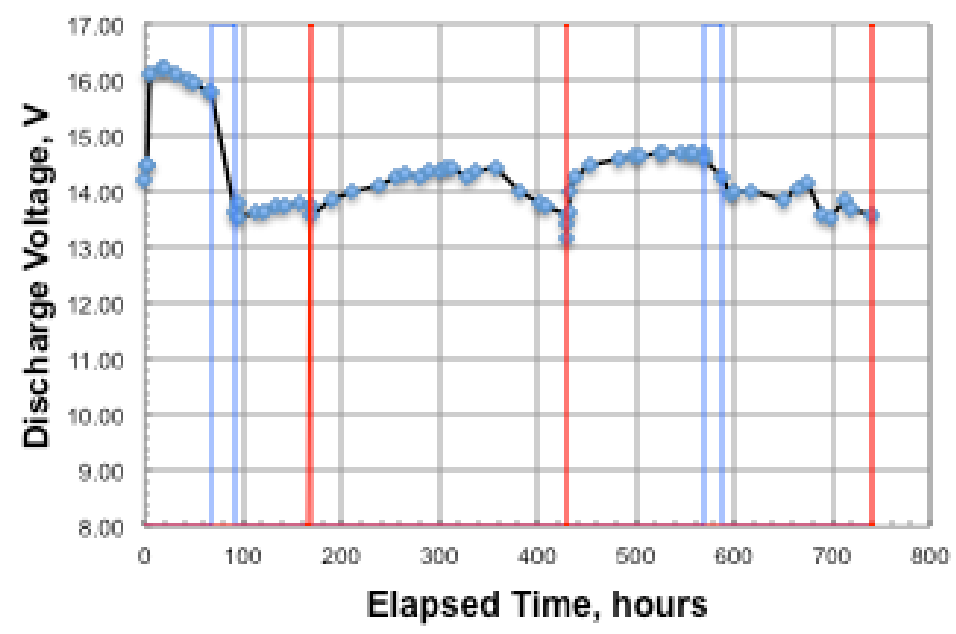
discharge current.

Figure 8. Discharge Voltage behavior. Markers indicated test interruptions (blue = perf. char.; red $=$ shutdowns) 


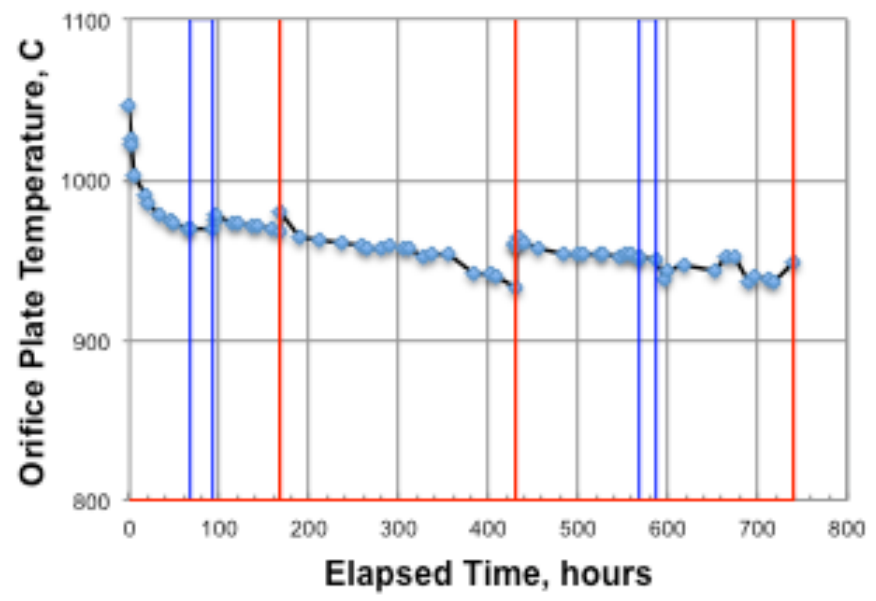

Figure 9. Cathode Orifice Plate Temperature behavior. Temperature measured with type $\mathbf{R}$ thermocouple attached to cathode outer edge of the orifice plate

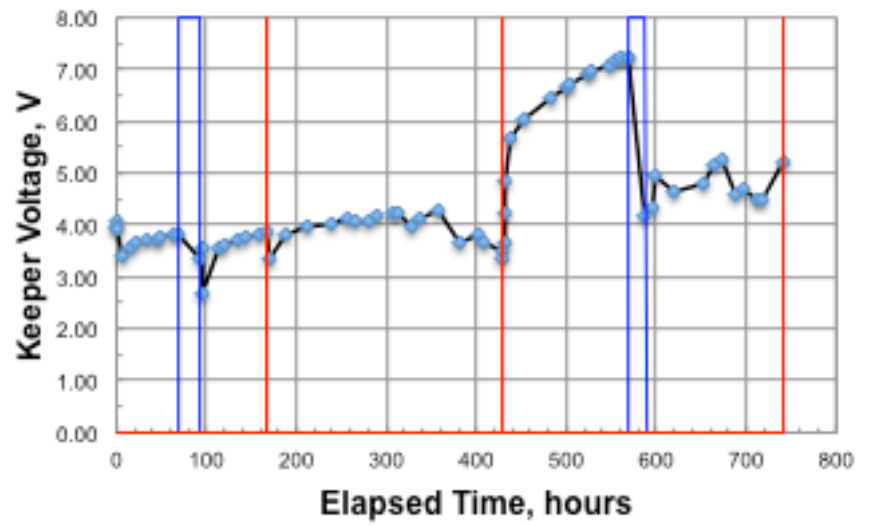

Figure 10. Cathode Keeper Voltage behavior. Keeper electrode is electrically floating during the wear-test

The markers on the graphs indicate test interruptions, with subsequent cathode re-start. The blue markers are planned interruptions, primarily the performance characterizations. The red markers indicate unplanned interruptions that to date have all occurred as the result of intermittent spikes in the facility vacuum pressure, where the pressure rises by approximately a decade before recovering within a few seconds. The step-changes in the voltages, followed by recovery to nominal operating levels, was not unexpected for hollow cathodes. The relatively larger change in keeper voltage following the shutdown at hour 430 is likely attributed to the collection of residual atmospheric gases during cryogenic pump regeneration at that time. Since the keeper is a floating electrode except for those times when the keeper supply is engaged during performance characterizations, this behavior suggests that there is no mechanism for cleaning the keeper electrode at nominal conditions. When the conditions were changed during the performance characterization at hour 569-588, removal of the hypothesized coating appears to have occurred, so that the keeper voltage recovered to approximately the values measured during the first performance characterization.

\section{Performance Characterization Comparison}

Two performance characterizations have been made during this wear-test. The results were assessed by comparing: discharge voltage, cathode orifice plate temperature, and keeper voltage as function of discharge current 
and flow rates. First, discharge voltage measurements shown in Figure 11 exhibited similar behavior between the two characterizations indicating relatively little change in cathode condition.
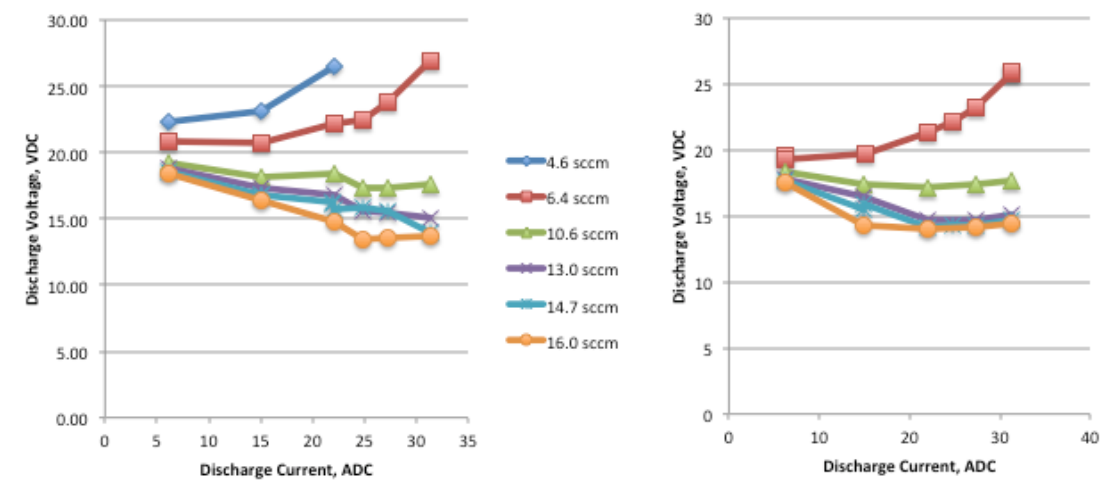

Figure 11. Discharge Voltage vs.

Current during performance characterization. Data on left captured at hour 68-78, data on right measured at hour 569-588

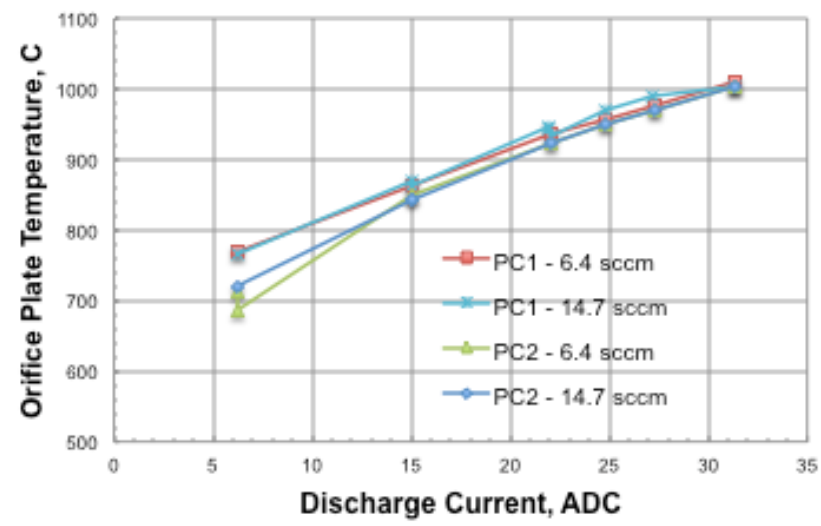

Figure 12. Cathode Orifice Plate Temperature vs. Discharge Current. Representative data from two flow rates collected during the first (PC1) and second (PC2) Performance Characterization

Second, cathode orifice plate temperature measurements indicated little sensitivity to flow rate so the representative data in Figure 12 illustrates the relatively small changes in temperature over most of the current range. It is unclear why the temperature exhibited the greatest decrease at the lowest discharge current.
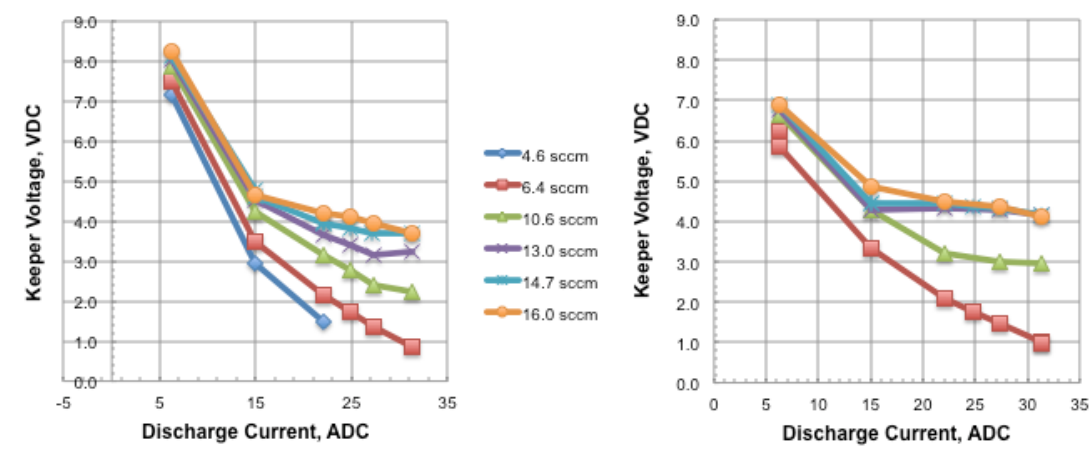

Figure 13. Keeper voltage vs. discharge current at various flow rates. Data on the left is for PC1;Data on right is for PC2 
Third, the keeper voltage behavior showed good agreement in Figure 13 between the performance characterizations. This suggests that the cause of the increased voltages readings prior to the second characterization was removed in subsequent operation. During the performance characterizations performed to date, nearly all of the conditions listed in in Table 2 were achieved. However some conditions were avoided if the resulting conditions exceeded safe limits (30 V for discharge voltage). Some of the test conditions during keeper-only operation were also skipped because the keeper voltage also exceeded the $30 \mathrm{~V}$ limit. This behavior occurred during no-magnetic field operation and is attributed to the cathode operating too cool.

\section{Summary Remarks}

Hollow cathode component wear-testing has been undertaken as part of an assessment of cathode emitter options for the HERMeS Hall thruster. The work summarized in this report is one of a series wear-tests being performed as part of a multi-phase effort to quantity the implementation benefits of either barium-based impregnated or LaB6 emitters in a hollow cathode assembly that can deliver the required emission current for the lifetime of the thruster. A hollow cathode assembly with a barium-oxide impregnated emitter operated with a Hall thruster simulator anode has accumulated 740 hours out of a planned 2,000 hours. Cathode operation has been stable as represented by the discharge voltage and cathode orifice plate temperature measurements. Minor changes in keeper voltage were observed that is believed to be due to atmospheric contamination during vacuum interruptions. The keeper voltage recovered after these events with continued cathode operation. Examination of the discharge voltage, cathode temperature, and keeper voltage during periodic characterizations has also shown stable performance to date.

\section{References}

\footnotetext{
${ }^{1}$ Herman et al., “The Ion Propulsion System for the Asteroid Redirect Robotic Mission,” AIAA 2016-0527, AIAA Propulsion \& Energy 2016, Salt Lake City, Utah, July 25-27, 2016

${ }^{2}$ Shastry, R., “End-of-Test Performance and Wear Characterization of NASA's Evolutionary Xenon Thruster (NEXT) Long Duration Test,” AIAA 2014-3617, 50 ${ }^{\text {th }}$ AIAA/ASME/SAE/ASEE Joint Propulsion Conference, Propulsion \& Energy Forum, 2014.

${ }^{3}$ Goebel, D.M., and, Watkins, R.M., “LaB6 Hollow Cathodes for Ion and Hall Thrusters,” AIAA 2005-4239, 41 ${ }^{\text {st }}$ AIAA/ASME/SAE/ASEE Joint Propulsion Conference \& Exhibit, Tucson, AZ, July 10-13, 2005.

${ }^{4}$ Goebel, D, "Lanthanum Hexaboride Hollow Cathode Performance and Wear Testing for the Asteroid Redirect Robotic Mission Hall Thruster," AIAA-2016-4835, AIAA Propulsion \& Energy 2016, July 25-27, 2016.

${ }^{5}$ Polk, J., Personnel Communication, July 2016

${ }^{6}$ Goebel, D. and Katz, I., Fundamentals of Electric Propulsion: Ion and Hall Thrusters, JPL Space Science and Technology Series, 2008.

${ }^{7}$ Cronin, J.L., “Modern Dispenser Cathodes,” IEE PROC. Vol. 128, Pt. 1, No. 1, Feb. 1981. Available at cathode.com.
} 
${ }^{8}$ Kamhawi, H., et al., "Update on the Operational Status of the International Space Station Plasma Contactor Hollow Cathode Assemblies for July 2011-May 2013,” AIAA 2013-4114, 49 ${ }^{\text {th }}$ AIAA/ASME/SAE/ASEE Joint Propulsion Conference, San Jose, CA, July, 2013.

${ }^{9}$ Polk, J., et al., "Performance of the NSTAR ion propulsion system on the Deep Space One mission,” 39"h Aerospace Sciences Meeting \& Exhibit, Reno, NV, Jan. 2001.

${ }^{10}$ Garner, C., et al, "In-Flight Operation of the Dawn Ion Propulsion System Through the Preparations for Escape from Vesta,” AIAA 2012-4182, 48 ${ }^{\text {th }}$ AIAA/ASME/SAE/ASEE Joint Propulsion Conference \& Exhibit, Atlanta, GA, July 30-Aug. 1, 2012

${ }^{11}$ Van Noord, J., "NASA’s Evolutionary Xenon Thruster (NEXT) Ion Propulsion System - Service Life Assessment," NASA/TM-2007-214910, Dec. 2007

${ }^{12}$ Polk, J. E., et al, “Scanning optical pyrometer for measuring temperatures in hollow cathodes,” Rev. Sci. Inst., 78, 093101 (2007).

${ }^{13}$ Goebel, D.M., et al, “Hollow cathode theory and experiment. I. Plasma characterization using fast miniature scanning probes,” J. Appl. Phys., 98, 113302 (2005)

${ }^{14}$ Lopez Ortega, A., "First-Principles Modeling of the Iat-Driven Anomalous Resistivity in Hollow Cathode Discharges II: Numerical Simulations and Comparison with Experiments," AIAA-2016-4627, AIAA Propulsion \& Energy 2016, Salt Lake City, UT, July 25-27, 2016.

${ }^{15}$ Williams, G., et al, "2000-hour Wear-Testing of the HERMeS Thruster," AIAA-2016-5025, AIAA Propulsion \& Energy 2016, Salt Lake City, UT, July 25-27, 2016.

${ }^{16}$ Kohl, W.H., Handbook of Materials and Techniques for Vacuum Devices, New York: Reinhold, 1967, pp. 494. 